\title{
Inter-relação entre COVID-19, periodontite e algumas doenças orais: revisão da
}

\section{literatura}

Interrelation Between COVID-19, periodontitis and some oral diseases: literature review

Interrelación entre COVID-19, periodontitis y algunas enfermedades orales: revisión de la literatura

Sâmylla Moita Lopes

ORCID: https://orcid.org/0000-0002-8059-9329 Universidade Federal do Delta do Parnaíba, Brasi E-mail: samylla.moita@hotmail.com

Weleson Matheus de Araújo Sousa ORCID: https://orcid.org/0000-0001-9889-883X Universidade Federal do Delta do Parnaíba, Brasi E-mail: estudanoselew@gmail.com Even Herlany Pereira Alves

ORCID: https://orcid.org/0000-0001-7566-1282 Universidade Federal do Delta do Parnaíba, Brasi E-mail: evenherlany@ufpi.edu.br

Jacks Renan Neves Fernandes

ORCID: https://orcid.org/0000-0001-7868-0673 Universidade Federal do Delta do Parnaíba, Brasil E-mail: jacks.renan@ifpi.edu.br

Thayaná Ribeiro Silva Fernandes ORCID: https://orcid.org/0000-0002-6590-4620 Universidade Federal do Delta do Parnaíba, Brasil E-mail: thayana.fernandes@hotmail.com

Valéria de Fátima Veras de Castro ORCID: https://orcid.org/0000-0001-8281-3029 Universidade Federal do Delta do Parnaíba, Brasi E-mail: castrovaleria701@gmail.com

Hélio Mateus Silva Nascimento

ORCID: https://orcid.org/0000-0003-1551-8139

Universidade Federal do Delta do Parnaíba, Brasi E-mail: helio_mateus_@hotmail.com

Wesley Rodrigues da Silva

ORCID: https://orcid.org/0000-0002-2241-5843

Universidade Federal do Delta do Parnaíba, Brasi E-mail: mr.wesleyrodrigues@gmail.com

John Arlley Sousa Pinho de Lira

ORCID: https://orcid.org/0000-0001-6565-6260

Universidade Federal do Delta do Parnaíba, Brasil

E-mail: arlley_pinho@hotmail.com

Francisco Alex da Rocha Coelho

ORCID: https://orcid.org/0000-0002-3308-375X

Universidade Federal do Delta do Parnaíba, Brasil E-mail: alex123rocha@hotmail.com

Paulo Roberto Carneiro Gomes

ORCID: https://orcid.org/0000-0002-2911-7785 Universidade Federal do Delta do Parnaíba, Brasi E-mail: paulo.c.gomes1@outlook.com

Fábio de Oliveira Silva Ribeiro

ORCID: https://orcid.org/0000-0002-3916-9239

Universidade Federal do Delta do Parnaíba, Brasi

E-mail: fabioriber2014@gmail.com

\section{Resumo}

O objetivo deste trabalho foi avaliar por meio de uma revisão a interrelação entre COVID-19, periodontite e algumas patologias orais. A transmissão da COVID-19 se dá por pequenas gotículas do nariz ou boca contendo a partícula viral que é expelida por pessoas durante a tosse, fala ou espirro, por exemplo. Cerca de $20 \%$ das pessoas infectadas 
necessitam de internação e 5\% provavelmente precisará de um leito em terapia intensiva. Pessoas com problemas médicos subjacentes, têm maior probabilidade de desenvolver doença graves. Pacientes que apresentam comorbidades preexistentes como, diabetes, hipertensão, doenças cardiovasculares, entre outras, podem estar mais suscetíveis a desenvolver a forma mais grave da COVID-19. Diversas alterações sistêmicas podem estar associadas à essa patologia, como, desordens na microbiota oral, aumentando o número de microrganismos nela presente, o que levaria a uma maior propensão às patologias orais. A entrada do vírus pode subverter o sistema imunológico e a microbiota oral do hospedeiro, desencadeando uma disbiose que permite uma superinfecção, compreensão da associação da doença periodontal com COVID-19 grave. Tendo isso em vista, o presente estudo visa avaliar a associação entre patologia oral e agravamento do COVID-19, assim como identificar sua relação de sintomas preexistentes às patologias orais.

Palavras-chave: COVID-19; Patologia bucal; Periodontite.

\begin{abstract}
:
The aim of this study was to evaluate, through a review, the interrelationship between COVID-19, periodontitis and some oral pathologies. The transmission of COVID-19 occurs through small droplets in the nose or mouth containing a viral particle that is expelled by people during coughing, speaking, or sneezing, for example. About $20 \%$ of those infected from inpatient and 5\% will likely occur from a bed in intensive care. People with underlying medical conditions are more likely to develop serious illness. Patients with preexisting comorbidities such as diabetes, hypertension, cardiovascular diseases, among others, may be more susceptible to developing the most severe form of COVID-19. Several systemic changes may be associated with this pathology, such as disorders in the oral microbiota, an increase in the number of microorganisms present in it, which would lead to a greater propensity for oral pathologies. Virus entry can subvert the host's immune system and oral microbiota, triggering dysbiosis that allows for superinfection, understanding the association of periodontal disease with severe COVID-19. The present study aims to assess an association between pathology oral and the worsening of COVID-19, as well as to identify its relationship between preexisting symptoms and oral pathologies.
\end{abstract}

Keywords: COVID-19; Pathology oral; Periodontitis.

\title{
Resumem:
}

El objetivo de este trabajo fue evaluar, a través de una revisión, la interrelación entre COVID-19, periodontitis y algunas patologías bucales. La transmisión de COVID-19 se realiza para pequenos gotitas de la nariz o la boca que contienen la partícula viral que es expulsada por las personas durante toser, hablar o estornudar, por ejemplo. Aproximadamente el $20 \%$ de las personas infectadas necesitan ingreso y el 5\% probablemente necesitará una cama de cuidados intensivos. personas com Los problemas médicos subyacentes tienen más probabilidades de desarrollar una enfermedad grave. Pacientes con comorbilidades preexistentes como diabetes, hipertensión, Las enfermedades cardiovasculares, entre otras, pueden ser más susceptibles a desarrollar la forma más grave de COVID-19. Se pueden asociar varios cambios sistémicos con este patología, como trastornos en la microbiota oral, aumentando el número de microorganismos presente en él, lo que conduciría a una mayor propensión a las patologias bucodentales. Entrada de vírus puede subvertir el sistema inmunológico y la microbiota oral del huésped, provocando una disbiosis que permite una sobreinfección, entendiendo la asociación de la patologia periodontal con COVID-19 severo. Teniendo esto en cuenta, este estudio tiene como objetivo evaluar la asociación entre patologías bucales y agravamiento de COVID-19, así como identificar su relación de los síntomas preexistentes con las patologías bucales.

Palabras clave: COVID-19; Patología bucal; Periodontitis.

\section{Introdução}

De acordo com a Organização Mundial da saúde, a COVID-19 originou-se na China após ser identificado como um conjunto de causas de pneumonia em Wuhan, na China. O patógeno foi identificado como um novo betacoranavírus com envelope de RNA, atualmente denominado síndrome respiratória aguda grave de Coronavírus 2 (SARS-CoV-2) (Mcintosh, Hirsch \& Bloom, 2020). Coronavírus são vírus de RNA com envelope amplamente distribuídos entre humanos, outros mamíferos e aves que causam doenças respiratórias, entéricas, hepáticas e neurológicas (Zhu et al., 2020).

A pandemia do Coronavírus teve vários impactos sociais, econômicos, culturais e políticos. Estima-se que os infectados e os mortos competem diretamente com o impacto no sistema de saúde, com a exposição da população e grupos de risco, afetando o sistema financeiro e suporte econômico da população (Fiocruz, 2021). Foram registrados mais de 156 milhões de caso de COVID-19 no mundo, e houve um constante crescimento, tendo uma média diária de 823.839 mil casos por dia. A transmissão da COVID-19 se dá por pequenas gotículas do nariz ou boca contendo a partícula viral que é expelida por pessoas 
durante a tosse, fala ou espirro, por exemplo. Essas partículas virais depositam-se em objetos ou superfícies, que ao serem tocadas e depois inoculados nos olhos, nariz ou boca contaminam as pessoas no qual tiveram o contato com os objetos (Gatti, M. et al., 2020). Os sintomas são: febre, cansaço e tosse seca. Alguns pacientes apresentam dores, congestão nasal, coriza e dor de garganta, e a maioria das pessoas contaminadas são assintomáticas (Gatti, et al., 2020).

Pacientes que apresentam comorbidades preexistentes como, diabetes, hipertensão, doenças cardiovasculares, entre outras, podem estar mais suscetíveis a desenvolver a forma mais grave da COVID-19 (Marouf, et al., 2021). Diversas alterações sistêmicas podem estar associadas à essa patologia, como, desordens na microbiota oral, aumentando o número de microrganismos nela presente, o que levaria a uma maior propensão às patologias orais. Estudos demonstram que a periodontite, caracterizada por ser uma infecção crônica, também pode estar relacionada ao agravamento no quadro clínico de pacientes acometidos da COVID-19, pois, o SARS-CoV-2 possui afinidade para receptores da enzima conversora de angiotensina $2\left(\mathrm{ACE}_{2}\right)$, que são biomarcadores para doenças cardiovasculares, cujo receptores estão presentes na mucosa oral.

Na COVID-19 grave, foi relatado que pacientes hospitalizados com intubação ou algum mecanismo invasivo prejudicaria sua saúde bucal. Dentro de uma análise metagenômica de pacientes com COVID-19 graves relataram o surgimento de gêneros Prevotella, Fusobacterium, Veillonella, que estão associados à doença periodontal. A entrada do vírus pode subverter o sistema imunológico e a microbiota oral do hospedeiro, desencadeando uma disbiose que permite uma superinfecção, compreensão da associação da doença periodontal com COVID-19 grave (Pitones-Rubio, V. et al, 2020). Sendo assim, compreender esta associação reforça a importância de manter o estado da doença periodontal controlada no manejo clínico de pacientes com COVID-19, porque a melhoria da saúde periodontal pode desempenhar um papel na redução do risco de complicações graves da COVID-19 (Bhatia, et al., 2021).

Neste contexto, o presente estudo visa avaliar a associação entre doenças orais e agravamento da COVID-19, assim como, identificar sua relação de sintomas preexistentes.

\section{Metodologia}

Estratégia de busca: uma busca foi realizada nas bases de dados Google Scholar, PubMed, SciELO, MEDLINE e LILACS para coleta de estudos publicados anteriormente à 08 de abril de 2021. Foram utilizados os descritores específicos nos idiomas propostos, inglês, espanhol e português: "Periodontite e COVID-19", "Patologias orais e COVID19", "SARS-CoV-2 e inflamações orais", "SARS-CoV-2 e periodontite" com a utilização de operadores booleanos entre os termos. Os resumos e as referências dos artigos foram revisados para identificação de possíveis estudos relevantes. Houve restrição de linguagem na coleta dos estudos, sendo os mesmos correspondentes aos idiomas inglês, espanhol e português.

\subsection{Critérios de inclusão:}

Foram inclusos na revisão sistemática estudos que abordassem tópicos que avaliaram a inter-relação entre periodontite e COVID-19. Foram incluídos artigos originais, de língua inglesa, espanhola ou portuguesa. Estudos não originais e/ou que não continham dados suficientes para a construção do trabalho em questão foram excluídos da análise.

\subsection{Critérios de exclusão:}

Foram excluídos trabalhos que não fossem artigos na íntegra de que se apresentavam incompletos, dissertações e/ou teses e metanálises. 


\subsection{Extração dos dados:}

A extração de dados foi realizada seguindo um formulário padronizado por: primeiro autor e ano de publicação, título do trabalho, metodologia utilizada, resultados encontrados e conclusão dos estudos (Brito, L. F. N. et al., 2016).

\section{Resultados}

A busca resultou em 31 estudos nas três bases de dados utilizadas (Google Scholar = 15, PubMed = 13, LILACS=3), como indicado na (Figura 1). Foram inclusos, na revisão sistemática, 15 estudos listados no (Quadro 1). Após a seleção dos trabalhos pelo primeiro autor, ano de publicação e título do trabalho a primeira exclusão foi realizada, pois se observou que não estavam dentro dos critérios propostos pelo objetivo deste trabalho. Após exclusão dos que não estavam dentro dos critérios de inclusão, os demais estudos tiveram leitura integral de seu conteúdo para então concluir a seleção dos estudos que fariam parte da revisão.

Figura 1: Fluxograma para identificação, avaliação, coleta e análise dos estudos inclusos na revisão sistemática realizada nas bases de dados Google Scholar, Pubmed e LILACS.
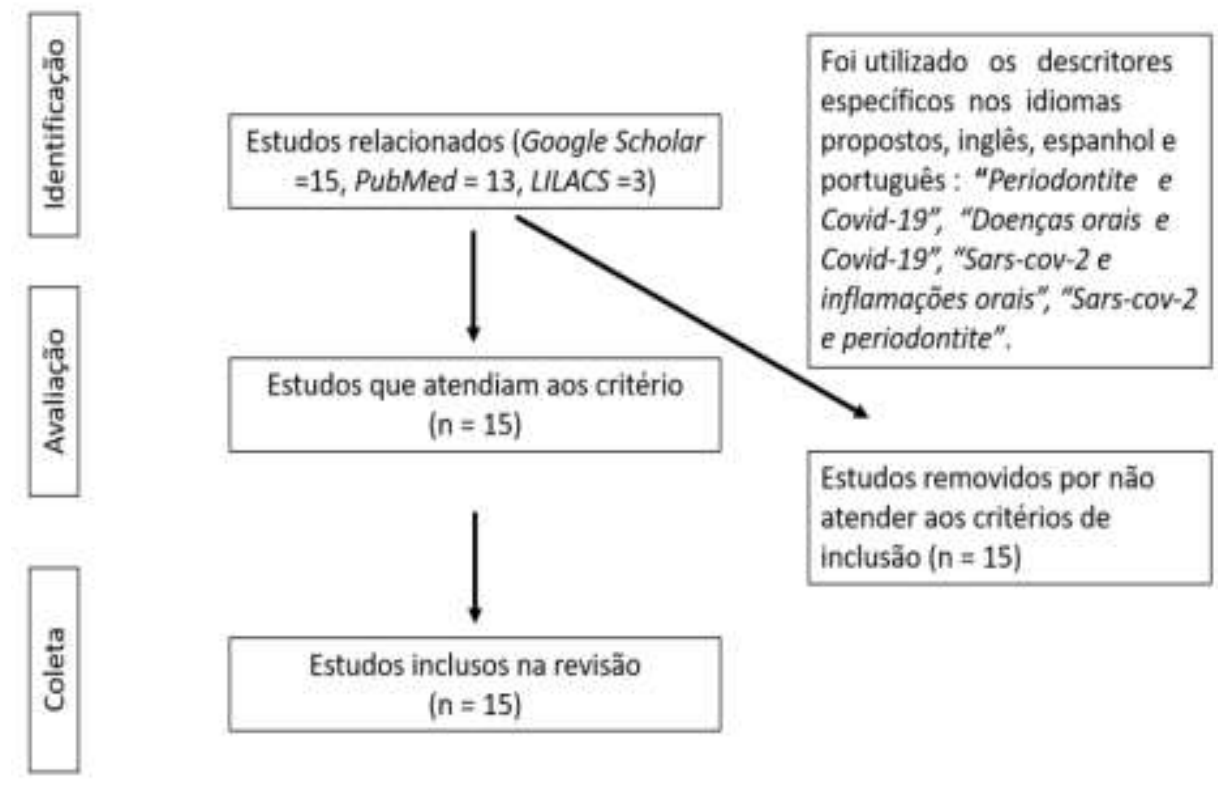

Fonte: Autores.

Quadro 1. Resultados dos estudos inclusos na revisão sistemática.

\begin{tabular}{|c|c|c|c|}
\hline Autor e Título & Método & Resultados encontrados & Conclusão \\
\hline $\begin{array}{c}\text { 1. Kara, } \\
\text { Cankat et al., } 2020 . \\
\text { Is periodontal disease a risk } \\
\text { factor for developing } \\
\text { severe COVID-19 } \\
\text { infection? } \\
\text { The potential role of } \\
\text { Galectin-3. }\end{array}$ & $\begin{array}{c}\text { Revisão de } \\
\text { literatura }\end{array}$ & $\begin{array}{l}\text { Uma área importante na proteína de pico do } \\
\text { SARSCoV-2 é quase o mesmo que a morfologia de } \\
\text { Gal-3, e essas proteínas de pico são críticas para a } \\
\text { entrada do vírus nas células hospedeiras. Esta relação } \\
\text { pode ser causada pelo aumento da resposta } \\
\text { imunológica mediada por Gal-3 e aumento da resposta } \\
\text { viral acessório. }\end{array}$ & $\begin{array}{l}\text { O aumento dos níveis de Gal-3 está } \\
\text { associado com a gravidade dos PDs e pode } \\
\text { ser usado como um fator positivo reagente } \\
\text { de fase aguda em PDs. Suspeitamos que há } \\
\text { evidências suficientes para apoiar uma } \\
\text { relação próxima entre a gravidade da } \\
\text { periodontite e Infecções por COVID-19 } \\
\text { Esta relação pode ser causada por aumento } \\
\text { da resposta imunológica mediada por Gal- } 3 \\
\text { e aumento da ligação viral. }\end{array}$ \\
\hline $\begin{array}{l}\text { 2. Falcón- Guerrero, } \\
\text { Britto E.; Falcon- } \\
\text { Pasapera, } \\
\text { G. S., 2021. } \\
\text { Repercusiones en la } \\
\text { Cavidad Oral }\end{array}$ & $\begin{array}{c}\text { Revisão de } \\
\text { literatura }\end{array}$ & $\begin{array}{l}\text { Os dentistas desempenham um papel importante ao } \\
\text { detectar e apoiar o diagnóstico precoce, uma vez que } \\
\text { os efeitos que essa infecção causa na cavidade oral e } \\
\text { que estão relacionadas ao início desse processo } \\
\text { infeccioso. Esses efeitos podem estar relacionados à } \\
\text { presença do vírus SARS-CoV-2 ou às formas de } \\
\text { tratamento que são administradas ao paciente, e }\end{array}$ & $\begin{array}{l}\text { A saúde bucal deve ser parte integrante do } \\
\text { manejo da COVID-19 devido à presença de } \\
\text { repercussões que ocorrem como um efeito } \\
\text { direto do vírus SARS-CoV-2, como } \\
\text { resultado dos tratamentos a que são } \\
\text { submetidos pacientes ou negligência da } \\
\text { higiene oral quando o paciente está }\end{array}$ \\
\hline
\end{tabular}




\begin{tabular}{|c|c|c|c|}
\hline $\begin{array}{c}\text { Causadas por la Infección } \\
\text { con COVID-19. }\end{array}$ & & prejudiciais à saúde bucal dos pacientes. & $\begin{array}{l}\text { prostrado. Então os dentistas precisam estar } \\
\text { preparados para realizar um exame clínico } \\
\text { adequado antes de qualquer tratamento para } \\
\text { detectar se há lesões na mucosa oral que } \\
\text { pode ser considerada como os primeiros } \\
\text { sinais de infecção com SARS-CoV-2. }\end{array}$ \\
\hline $\begin{array}{l}\text { 3. Bhatia, V. et al., } 2021 . \\
\text { Can Improved } \\
\text { Periodontal Health } \\
\text { Be A Key Factor In } \\
\text { Preventing Severe } \\
\text { COVID-19 } \\
\text { Complications: Na } \\
\text { EvidenceBased Review. }\end{array}$ & $\begin{array}{c}\text { Revisão de } \\
\text { literatura }\end{array}$ & $\begin{array}{l}\text { A COVID-19 é agora reconhecida como uma } \\
\text { pandemia em todo o mundo e a gravidade da doença } \\
\text { tem sido atribuído a muitos fatores de risco médicos } \\
\text { relacionados ao paciente, que incluem diabetes, } \\
\text { hipertensão, doenças respiratórias, doenças } \\
\text { cardiovasculares e doenças renais crônicas devido à } \\
\text { resposta imune exagerada associada a estas doenças }\end{array}$ & $\begin{array}{l}\text { Há evidências emergentes para apoiar que } \\
\text { doenças periodontais podem ser um fator de } \\
\text { risco potencial para infecção por COVID-19 } \\
\text { por causa da associação de doenças } \\
\text { periodontais com várias doenças e } \\
\text { condições sistêmicas }\end{array}$ \\
\hline $\begin{array}{l}\text { 4. Passarelli, } \\
\text { P. C. et al., 2020. } \\
\text { COVID-19 and Oral } \\
\text { Diseases: How Can We } \\
\text { Manage } \\
\text { Hospitalized and } \\
\text { Quarantined } \\
\text { Patients while } \\
\text { Reducing Risks? }\end{array}$ & $\begin{array}{c}\text { Revisão de } \\
\text { literatura }\end{array}$ & $\begin{array}{l}\text { Sabemos a importância de gerenciar a saúde bucal de } \\
\text { pacientes com COVID-19 e o risco de adquiri-lo em } \\
\text { todos os profissionais de saúde. As patologias dentais } \\
\text { são muito frequentes e existe o risco de se enfrentar } \\
\text { muitas emergências dentárias nas semanas e meses } \\
\text { seguintes. Portanto, foram propostos alguns simples } \\
\text { procedimentos que tentam evitá-los. }\end{array}$ & $\begin{array}{l}\text { Devemos estar cientes do alto risco de } \\
\text { infecção por COVID-19 em profissionais de } \\
\text { saúde, sobretudo dentistas. Por outro lado, } \\
\text { muitas pessoas podem atualmente precisar } \\
\text { de curas dentais e o profissional deve ter } \\
\text { protocolos práticos e fáceis de fazer para } \\
\text { evitar infecções cruzadas potenciais. }\end{array}$ \\
\hline $\begin{array}{c}\text { 5. Marouf, } \\
\text { Nadya et al., 2021. } \\
\text { Association between } \\
\text { periodontitis and } \\
\text { severity of COVID-19 } \\
\text { infection: A case- control } \\
\text { study. }\end{array}$ & $\begin{array}{c}\text { Caso } \\
\text { controle }\end{array}$ & $\begin{array}{l}\text { A periodontite foi associada à complicação COVID19, } \\
\text { incluindo morte (OR }=8,81 \text {, IC de 95\% 1,00-77,7), } \\
\text { admissão na UTI (OR }=3,54 \text {, IC 95\% } 1,39-9,05) \text { e } \\
\text { necessidade de ventilação assistida (OR }=4,57 \text {, IC 95\% } \\
\text { 1,19-17,4). Da mesma forma, os níveis sanguíneos de } \\
\text { glóbulos brancos, dímero-D e a proteína C reativa foram } \\
\text { significativamente maiores. }\end{array}$ & $\begin{array}{l}\text { A periodontite foi associada a maior risco de } \\
\text { admissão na UTI, necessidade de ventilação } \\
\text { assistida e morte de pacientes COVID- } 19 \text {, e } \\
\text { com aumento dos níveis sanguíneos de } \\
\text { biomarcadores ligados a piores resultados da } \\
\text { doença. }\end{array}$ \\
\hline $\begin{array}{l}\text { 6. Cardoso et al., } 2020 . \\
\text { COVID-19 e a Cavidade } \\
\text { Bucal: } \\
\text { Interações, } \\
\text { Manifestações } \\
\text { Clínicas e } \\
\text { Prevenção. }\end{array}$ & $\begin{array}{c}\text { Revisão de } \\
\text { literatura }\end{array}$ & $\begin{array}{l}\text { Cirurgiões-Dentistas fazem parte dos profissionais de } \\
\text { saúde sujeitos tanto a adquirir quanto transmitir o } \\
\text { SARS-CoV-2, devido à proximidade com o paciente } \\
\text { durante o atendimento e às características dos } \\
\text { procedimentos realizados, que podem levar à formação } \\
\text { de aerossóis ou disseminação de partículas de saliva e } \\
\text { sangue, podendo contaminar diversas superfícies e } \\
\text { promover infecção cruzada. }\end{array}$ & $\begin{array}{l}\text { Diversas manifestações clínicas foram } \\
\text { diagnosticadas na cavidade bucal em } \\
\text { indivíduos com COVID-19 como sia adenite, } \\
\text { anosmia, ageusia e ulcerações, dentre outras. } \\
\text { Devido às características dos procedimentos } \\
\text { odontológicos, que podem envolver a } \\
\text { disseminação de partículas de saliva e } \\
\text { formação de aerossóis. }\end{array}$ \\
\hline $\begin{array}{l}\text { 7. Fernandes Matuck, } \\
\text { Bruno et al., 2021. } \\
\text { Periodontal tissues are targets } \\
\text { for Sars- } \\
\text { Cov-2: a postmortem study. }\end{array}$ & $\begin{array}{c}\text { Estudo } \\
\text { postmortem }\end{array}$ & $\begin{array}{l}\text { As sete autópsias estudadas com testes laboratoriais } \\
\text { positivos para a COVID-19 incluíram } 57,14 \% \text { de } \\
\text { pacientes do sexo feminino com a idade média de } 47,4 \\
\text { anos. Em cinco casos, o tecido periodontal foi positivo } \\
\text { para a SARS-CoV-2. As análises histopatológicas } \\
\text { mostraram alterações morfológicas nos queratinócitos } \\
\text { do epitélio juncional, uma vacuolização do citoplasma e } \\
\text { núcleo e pleomorfismo nuclear. }\end{array}$ & $\begin{array}{l}\text { Apresentamos uma análise biomolecular } \\
\text { obtida a partir de autópsias minimamente } \\
\text { invasivas. Este é o primeiro estudo a } \\
\text { demonstrar a presença da SARS-CoV-2 em } \\
\text { tecido periodontal em doentes positivos à } \\
\text { COVID-19. }\end{array}$ \\
\hline $\begin{array}{c}\text { 8. Sharma, } \\
\text { Anil et al.,2020. } \\
\text { Periodontitis associated with } \\
\text { Systemic } \\
\text { Diseases increases the case } \\
\text { fatality rate } \\
\text { among COVID-19 } \\
\text { Patients. }\end{array}$ & $\begin{array}{c}\text { Revisão } \\
\text { de } \\
\text { literatura }\end{array}$ & $\begin{array}{l}\text { A periodontite crônica juntamente com estas doenças } \\
\text { sistêmicas subjacentes e outras doenças por fatores } \\
\text { ambientais, são de risco comuns em pacientes com } \\
\text { COVID-19. Estas comorbidades e fatores aumentam a } \\
\text { Taxa de Fatalidade de Casos (CFR) entre pacientes da } \\
\text { COVID-19. Desde o estado de saúde periodontal, } \\
\text { pacientes com COVID- } 19 \text { não foram detectados até } \\
\text { agora, por isso é difícil de descobrir a relação entre a } \\
\text { periodontite crônica com a fatalidade de COVID-19. }\end{array}$ & $\begin{array}{l}\text { O estatuto periodontal como PPD, CAL, etc. } \\
\text { ainda não foi notificado. Apenas com base } \\
\text { em odontologia oral e o histórico médico } \\
\text { retirado dos pacientes da COVID-19 é que } \\
\text { chegamos na conclusão de que a periodontite } \\
\text { crónica e a COVID-19 em relação com a } \\
\text { doença poderia ajudar-nos a identificar os } \\
\text { grupos de risco e a estabelecer as } \\
\text { recomendações pertinentes. Identificando } \\
\text { estes grupos de risco de periodontite crônica } \\
\text { com doenças sistêmicas subjacentes, } \\
\text { podemos controlar o CFR. }\end{array}$ \\
\hline
\end{tabular}




\begin{tabular}{|c|c|c|c|}
\hline $\begin{array}{l}\text { 9. Sukumar, Kanchana; } \\
\text { Tadepall, Anupama. 2021. } \\
\text { Nexus between } \\
\text { COVID-19 and } \\
\text { periodontal disease. }\end{array}$ & $\begin{array}{c}\text { Revisão } \\
\text { de } \\
\text { literatura }\end{array}$ & $\begin{array}{l}\text { A investigação atual sugere que o aumento da libertação } \\
\text { de citocinas de células hospedeiras, referida como } \\
\text { tempestade de citocinas, está associada à progressão da } \\
\text { doença em doentes com COVID-19. Uma intersecção } \\
\text { entre periodontite e a doença pulmonar é biologicamente } \\
\text { plausível. Daí que temos revisto as provas que ligam a } \\
\text { COVID-19, citocinas, e doenças periodontais. O } \\
\text { controle de placas é essencial para evitar a troca de } \\
\text { bactérias entre a boca e os pulmões, reduzindo o risco de } \\
\text { doença pulmonar. Compreender estas associações pode } \\
\text { ajudar a identificar indivíduos em alto risco e a prestar } \\
\text { os cuidados adequados nas fases iniciais. }\end{array}$ & $\begin{array}{l}\text { As doenças periodontais podem aumentar } \\
\text { ainda mais libertação de citocinas através de } \\
\text { microflora alterada, expressão de múltiplos } \\
\text { receptores virais, bacterianos superinfecções, } \\
\text { e aspiração de periodontal agentes } \\
\text { patogénicos. O SARS-CoV-2 pode penetrar a } \\
\text { barreira hematoencefálica através do bolbo } \\
\text { olfativo. Embora o SARS- CoV-2 infecte } \\
\text { células apenas através de receptores ACE2, } \\
\text { os mecanismos através dos quais os vírus } \\
\text { induzem efeitos deletérios no sistema nervoso } \\
\text { central, continuam não sendo claros. As } \\
\text { relações entre o stress psicológico da } \\
\text { COVID-19 e a doença periodontal poderiam } \\
\text { ser mediada por respostas alteradas de } \\
\text { citocinas, após replicação viral. }\end{array}$ \\
\hline $\begin{array}{c}\text { 10. Flores, } \\
\text { RG; } \\
\text { Rodríguez, } \\
\text { GZ, 2020. } \\
\\
\text { Implicaciones bucales por } \\
\text { COVID-19. } \\
\text { Revisión de tema. }\end{array}$ & $\begin{array}{l}\text { Revisão } \\
\text { de } \\
\text { literatura }\end{array}$ & $\begin{array}{l}\text { Manifestações clínicas que contribuíram para a } \\
\text { compreensão do comportamento da SARS-CoV-2 foram } \\
\text { relatados; a área } \\
\text { médica dermatológica tem apresentado estudos sobre a } \\
\text { expressão da COVID-19na pele, por exemplo, mas em } \\
\text { nível oral as informações são limitadas. Os tecidos da } \\
\text { cavidade oral representam uma estrutura inicial } \\
\text { suscetível à infecção viral e fluidos orais como veículos } \\
\text { de transmissão. }\end{array}$ & $\begin{array}{l}\text { Nesse contexto, várias são as manifestações } \\
\text { clínicas que podem estar associadas à } \\
\text { COVID-19. A recuperação está relacionada à } \\
\text { melhora dos sintomas gerais causados pelo } \\
\text { vírus. Utilização de saliva para extrair o RNA } \\
\text { viral é uma fonte sólida para a detecção de } \\
\text { SARS-CoV-2. Pacientes com doença } \\
\text { periodontal podem estar associados à } \\
\text { patologias pulmonares, exacerbações ou } \\
\text { complicações das mesmas. }\end{array}$ \\
\hline $\begin{array}{c}\text { 11. Santos, JP A et al., } 2020 . \\
\text { Doença periodontal e } \\
\text { covid-19: O que podemos } \\
\text { inferir } \\
\text { da literatura até o presente } \\
\text { momento? }\end{array}$ & $\begin{array}{c}\text { Revisão } \\
\text { de } \\
\text { literatura }\end{array}$ & $\begin{array}{l}\text { Estudos têm sugerido possível relação com a COVID-19 } \\
\text { e peridontite. Não somente por serem patologias que } \\
\text { evoluem a partir do quadro inflamatório e em que se } \\
\text { ampara uma possível relação, evidências apontam, por } \\
\text { exemplo, a possibilidade de que as bolsas periodontais } \\
\text { sirvam como reservatório do SARS-CoV-2, bem como } \\
\text { existiria uma relação entre a atividade das citocinas, o } \\
\text { que ampliaria a sintomatologia da COVID-19. Outros } \\
\text { autores apontam uma maior quantidade de patógenos da } \\
\text { DP em portadores do SARS-CoV-2; maior } \\
\text { predisposição à periodontite necrosante; semelhança de } \\
\text { atuação de componentes celulares de defesa; facilitação } \\
\text { de infecção viral via ação molecular. }\end{array}$ & $\begin{array}{l}\text { Embora os estudos acerca da possível } \\
\text { associação da doença periodontal com a } \\
\text { COVID-19 ainda serem escassos, as } \\
\text { hipóteses levantadas pelos artigos trazem } \\
\text { resultados variados, cada um propondo um } \\
\text { tipo de associação, com características e } \\
\text { particularidades diferentes. Contudo, são de } \\
\text { suma importância para construção de uma } \\
\text { base que possibilitará estudos futuros de } \\
\text { caráter longitudinal tendo em vista que } \\
\text { apresentam múltiplas possibilidade de } \\
\text { associações. }\end{array}$ \\
\hline $\begin{array}{c}\text { 12. Bertolini, } \\
\text { Martinna et al., } 2020 . \\
\text { Periodontal } \\
\text { Disease in the } \\
\text { COVID-19 Era: Potential } \\
\text { Reservoir and Increased Risk } \\
\text { for SARS-CoV-2. }\end{array}$ & $\begin{array}{l}\text { Revisão } \\
\text { de } \\
\text { literatura }\end{array}$ & $\begin{array}{l}\text { A enzima conversora de angiotensina-2 (ACE-2) foi } \\
\text { considerada o principal receptor para a entrada do } \\
\text { SARS-CoV-2 nas células humanas, e sabe-se que estão } \\
\text { presentes não apenas nos pulmões (pneumonia viral } \\
\text { comum), mas também na mucosa nasofaringe, células } \\
\text { salivares e células epiteliais orais. Além disso, parece } \\
\text { haver evidências recentes mostrando que o fluido } \\
\text { clavicular nas bolsas periodontais de pacientes com } \\
\text { periodontite pode abrigar SARSCoV-2 e atuar como um } \\
\text { potencial reservatório para aumento da carga viral na } \\
\text { cavidade oral de pacientes COVID-positivos. Além } \\
\text { disso, pacientes com doença periodontal ativa podem } \\
\text { contribuir para a ligação do vírus e infecção do tecido } \\
\text { devido à expressão elevada de proteases de furina e } \\
\text { catepsina L, que desempenham um papel importante em } \\
\text { permitir que o SARS-CoV-2 se ligue à receptores ACE- } \\
2 \text {, facilitando a fusão endossomal nas células. }\end{array}$ & $\begin{array}{l}\text { Para combater a pandemia da COVID-19 de } \\
\text { forma eficiente, é crucial reduzir a } \\
\text { propagação da infecção não só realizando } \\
\text { medidas extraordinárias de prevenção e } \\
\text { segurança, mas também identificando } \\
\text { possíveis vírus reservatórios em pacientes } \\
\text { COVID-positivos, bem como identificar } \\
\text { potenciais alvos para intervenção antiviral na } \\
\text { infecção por SARS-CoV-2. Este artigo e } \\
\text { publicações recentes no campo periodontal } \\
\text { destacam que a terapia periodontal pode ser } \\
\text { considerada um parâmetro de cuidado no } \\
\text { manejo clínico global de pacientes } \\
\text { COVIDpositivos, visando a redução do } \\
\text { reservatório viral nas bolsas periodontais. O } \\
\text { tratamento periodontal ativo pode diminuir a } \\
\text { expressão de furina e catepsina L, reduzindo } \\
\text { a capacidade do SARS-CoV-2 de infectar as } \\
\text { células. }\end{array}$ \\
\hline $\begin{array}{l}\text { 13. Johnson, Ilona } \\
\text { G. et al., 2021. } \\
\text { Dental periodontal } \\
\text { procedures: a } \\
\text { systematic review of } \\
\text { contamination } \\
\text { (splatter, droplets and } \\
\text { aerosol) in relation to } \\
\text { COVID-19. }\end{array}$ & $\begin{array}{c}\text { Revisão } \\
\text { de } \\
\text { literatura }\end{array}$ & $\begin{array}{l}\text { Os resultados incluíram bactérias ou sangue } \\
\text { contaminação e contaminação não bacteriana, não } \\
\text { sanguínea (por exemplo, quimiluminescência ou } \\
\text { corantes coloridos). Todos os estudos encontraram } \\
\text { contaminação nos locais, embora a contaminação } \\
\text { associada à escamação manual fosse muito baixa. } \\
\text { Contaminação era identificados em todos os estudos, } \\
\text { mesmo quando a sucção foi usada no início do estudo. } \\
\text { Configurações de energia mais altas criaram maior } \\
\text { contaminação. A distribuição da contaminação variou } \\
\text { em relação à posição do operador e foi encontrada no } \\
\text { operador, paciente e assistente com níveis mais elevados } \\
\text { ao redor da cabeça do operador e da boca e tórax. }\end{array}$ & $\begin{array}{l}\text { Descamação ultrassônica, polimento de ar e } \\
\text { procedimentos de profilaxia produzem } \\
\text { contaminação (respingos, gotas e aerossol) na } \\
\text { presença de sucção, com pequena quantidade } \\
\text { de evidências mostrando gotículas que } \\
\text { demoram entre } 30 \text { min e } 1 \text { h para se } \\
\text { depositar. Deve-se levar em consideração o } \\
\text { controle de infecção, áreas de limpeza, } \\
\text { especialmente ao redor do paciente e pessoal } \\
\text { apropriados equipamentos de proteção, com } \\
\text { especial atenção à proteção respiratória, } \\
\text { facial e corporal para esses procedimentos. }\end{array}$ \\
\hline
\end{tabular}




\begin{tabular}{|c|c|c|c|}
\hline $\begin{array}{c}\text { 14. Takahashi, } \\
\text { Yuwa et al., 2021. } \\
\text { Aspiration of periodontopathic } \\
\text { bacteria due to poor oral } \\
\text { hygiene } \\
\text { potentially contributes } \\
\text { to the aggravation of } \\
\text { COVID-19 }\end{array}$ & $\begin{array}{c}\text { Revisão } \\
\text { de } \\
\text { literatura }\end{array}$ & $\begin{array}{l}\text { Bactérias periodontopáticas estão envolvidas em doenças } \\
\text { respiratórias, incluindo pneumonia de aspiração e doença } \\
\text { pulmonar obstrutiva crônica (DPOC) e outras doenças } \\
\text { sistêmicas, como diabetes e doenças cardiovasculares. } \\
\text { Pacientes com essas doenças têm uma taxa de } \\
\text { agravamento e mortalidade de COVID-19 muito altas. } \\
\text { Porque a aspiração de bactérias periodontopáticas induz a } \\
\text { expressão da enzima conversora de angiotensina } 2 \text {, um } \\
\text { receptor para SARS-CoV-2, e produção de citocinas } \\
\text { inflamatórias na parte inferior trato respiratório, a má } \\
\text { higiene oral pode levar ao agravamento da COVID-19. }\end{array}$ & $\begin{array}{l}\text { A aspiração de bactérias periodontopáticas em } \\
\text { pacientes com COVID-19 leva } \\
\text { potencialmente ao agravamento de COVID-19 } \\
\text { através da indução da produção de citocinas } \\
\text { inflamatórias, expressão de ACE2 e clivagem } \\
\text { da proteína S de SARS-CoV-2. O SARS- } \\
\text { CoV-2 pode invadir facilmente o tecido } \\
\text { periodontal de um paciente com lesões } \\
\text { periodontais. Entrada de bactérias } \\
\text { periodontopáticas e endotoxinas nos vasos } \\
\text { sanguíneos podem levar à bacteremia e } \\
\text { endotoxemia, aumentando assim a gravidade } \\
\text { de COVID19 em indivíduos com infecção por } \\
\text { SARS-CoV-2. }\end{array}$ \\
\hline $\begin{array}{c}\text { 15. Iranmanesh, } \\
\text { Behzad et al., 2021. } \\
\text { Oral manifestations of } \\
\text { COVID-19 disease: A review } \\
\text { article. }\end{array}$ & $\begin{array}{l}\text { Revisão } \\
\text { de } \\
\text { literatura }\end{array}$ & $\begin{array}{l}\text { As manifestações orais incluíram úlcera, erosão, bolha, } \\
\text { vesícula, pústula, língua fissurada ou despapilada, } \\
\text { mácula, pápula, placa, pigmentação, halitose, } \\
\text { esbranquiçadas áreas, crosta hemorrágica, necrose, } \\
\text { petéquias, edema, eritema e sangramento espontâneo. Os } \\
\text { locais mais comuns de envolvimento em ordem } \\
\text { decrescente foram língua, labial mucosa e palato. Os } \\
\text { diagnósticos sugeridos das lesões foram estomatite } \\
\text { aftosa, lesões herpetiformes, candidíase, vasculite, tipo } \\
\text { Kawasaki, tipo EM, mucosite, medicamento erupção, } \\
\text { doença periodontal necrosante, semelhante a angina } \\
\text { bolhosa, queilite angular, atípica Síndrome de Sweet e } \\
\text { síndrome de MelkersonRosenthal. Lesões orais eram } \\
\text { sintomáticas em } 68 \% \text { dos casos. }\end{array}$ & $\begin{array}{l}\text { Lesões aftosas, lesões herpetiformes, } \\
\text { candidíase e lesões orais da doença } \\
\text { semelhante a Kawasaki são as manifestações } \\
\text { orais mais comuns de Doença COVID-19. } \\
\text { Uma idade avançada e gravidade da doença } \\
\text { COVID-19 parecem ser os fatores mais } \\
\text { comuns que predizem a gravidade das lesões } \\
\text { nesses pacientes. Falta de higiene oral, } \\
\text { infecções oportunistas, estresse, doenças } \\
\text { subjacentes, trauma, comprometimento } \\
\text { vascular e resposta hiperinflamatória } \\
\text { secundária a COVID-19 pode ser os fatores } \\
\text { predisponentes mais importantes para o } \\
\text { desenvolvimento de doenças orais lesões em } \\
\text { pacientes COVID-19. }\end{array}$ \\
\hline
\end{tabular}

Fonte: Autores.

\section{Discussão}

Este trabalho traz uma avaliação da inter-relação entre patologias orais e COVID-19 com o objetivo de esclarecer sobre diversos fatores intrínsecos, clínicos e genéticos que já foram relacionados e descritos na literatura. (Pitones-Rubio, V. et al., 2020) sugeriram que a doença periodontal está relacionada a gravidade da COVID-19, dado que pacientes intubados mostraram uma deterioração da saúde bucal, produzindo disbiose da microbiota oral que poderia desencadear a doença periodontal. Também se observou que a COVID-19, junto com medidas terapêuticas e farmacológicas associadas, podem agravar as condições orais com etiologia dos mecanismos imunológicos podendo interferir com a dinâmica de equilíbrio da microbiota levando a várias infecções fúngicas oportunistas, xerostomia relacionada a diminuição do fluxo salivar, ulcerações e gengivite (Dziedzic, \& Wojtyczka, 2020).

Bhatia, et al. (2021) exploram e destacam os vários mecanismos para investigar a função da doença periodontal como um fator contribuinte para COVID-19 e complicações relacionadas. O sulco gengival é apontado como um desses mecanismos, é provável que o sulco gengival seja um nicho ecológico para a SARS-CoV-2, a presença de $\mathrm{ACE}_{2}$ que é o principal receptor para SARS-CoV-2 no epitélio de glândulas salivares e gengiva aponta esse potencial relação. Outro mecanismo associado a infecção por COVID-19 é a tempestade de citocinas, o aumento de IL-17 aponta para uma possível associação entre periodontite e complicações relacionadas à COVID-19. O último mecanismo apontando é a formação de armadilhas extracelulares de neutrófilos, níveis de interferon-alfa, o mediador envolvido na estimulação da liberação das armadilhas extracelulares de neutrófilos foi encontrado mais elevados em pacientes com doenças periodontais.

Marouf, et al. (2021), também investigou através de um caso controle a associação da periodontite e as complicações da COVID-19. Onde foi realizado um estudo com um total de 568 pacientes COVID-19-positivos, que foram selecionados para o estudo, 258 apresentaram periodontite. Entre os pacientes que apresentaram periodontite, 33 tiveram complicações, enquanto apenas 7 dos 310 pacientes sem periodontite apresentaram complicações. Como resultado, após a análise dos dados e o ajuste para possíveis fatores de confusão, a periodontite foi associada à complicação da COVID-19, incluindo morte, 
admissão na UTI e necessidade de ventilação assistida. Com esses resultados obtidos é possível afirmar a associação entre periodontite e piora de progressão de COVID-19.

Sukumar e Tadepalli (2021) complementa os achados relacionados as alterações sistêmicas ocasionadas pela periodontite e a infecção com SARS-CoV-2, entende-se que por meio dessas alterações a periodontite pode aumentar a gravidade de COVID19, podendo causar também disbiose microbioana, superinfecção bacteriana, hiper-responsividade do hospedeiro e superestimulação do sistema imunológico, além da tempestade de citocinas que aumenta a resposta inflamatória. É esclarecido que, havendo alteração da microbiota oral, poderá agravar infecções pela COVID-19.

Bertolini, et al. (2020) acredita que as bolsas periodontais possam ser reservatórios para SARS-CoV-2, já que apresentam interações com a cavidade oral e corrente sanguínea através de complexos capilares. A osteopontina, fosfoproteína glicosilada, demonstrou ser elevada na periodontite (Yongchaitrakul et al., 2009), onde, os níveis aumentados dessa fosfoproteína, ativarão o NFkB, que são fatores de transcrição que regulam chave das respostas imunológicas, inflamatórias e de fase aguda, e, também, implicados no controle da proliferação celular e apoptose (Rayet \& Gelinas, 1999), aumentando a expressão de furina (Kumar, et al, 2010). A expressão da Catepsina L, será aumentada pelos fibroblastos gengivais. Tanto a furina como a catepsina L desempenham um papel importante ao permitir que a SARS-CoV-2 infecte as células hospedeiras por clivagem de glicoproteínas da SARS-CoV-2. Sendo assim, pesquisadores sugerem que haja um tratamento periodontal para diminuir a expressão de furina e catepsina L, reduzindo a capacidade do SARS-CoV-2 de infectar as células hospedeiras.

No entanto, outras patologias orais podem estar associadas a COVOD-19 além da periodontite. (Falcón-Guerrero et al., 2021) realizaram uma revisão a fim de informar sobre as repercussões que podem ocorrer na cavidade oral por infecção com COVID-19. Afirma-se que os possíveis sintomas relacionados a cavidade oral incluem hipogeusia, xerostomia e alterações quimiossensorias, ressaltando que pacientes COVID-19 positivos apresentam diferentes graus de gravidade e aparecimento de alteração gustativas, corroborando assim com os estudos de Soares, et al. (2020) e Harikrishnan, et al. (2020). Além das gustativas, foi considerado que a COVID-19 pode causar lesões secundárias, como: lesões ulceradas que têm sido descritas em palato duro, língua e lábios, as quais poderiam ser uma reação primária ao SARS-CoV-2, uma vez que poucos dias após essa lesão, o paciente apresentou resultado positivo para COVID-19.

Takahashi et al. (2021), propuseram que à má higiene oral agrava a COVID-19 por alguns mecanismos sugeridos. O primeiro mecanismo sugerido é que bactérias periodontopáticas promovem infecção por SARS-CoV-2 por aumento da expressão de $\mathrm{ACE}_{2}$. $\mathrm{O}$ segundo mecanismo proposto é agravamento de COVID-19 induzido pela produção de citocinas inflamatórias do trato respiratório inferior por estimulação com bactérias periodontopáticas. O terceiro mecanismo apontando é a protease de bactérias periodontopáticas que pode promover a infecciosidade da SARS-CoV-2 pela degradação da proteína $\mathrm{S}$ de SARS-CoV-2. Na discussão foi argumentado que os mecanismos acima podem influenciar consideravelmente o agravamento de COVID-19. Uma breve conclusão que se pode tirar é que uma boa higiene oral é importante para manter uma boa saúde.

Cardoso et al. (2020) relataram que, os pacientes acometidos pela COVID-19 podem apresentar o aparecimento de alguns efeitos adversos na cavidade oral, assim como infecções relacionadas ao vírus e aparecimento de microrganismos que irão comprometer a saúde bucal. Estudos demonstraram que as manifestações orais mais comuns em pacientes de COVID-19 são: erosão, bolha, língua fissurada, mácula, sangramento, halitose, entre outros. Pacientes sob ventilação mecânica ou de UTI's, também terão a saúde bucal comprometida, devido à hipossalivação, que é a diminuição de produção de saliva. Sendo assim as mucosas orais ficarão desprotegidas e suscetíveis à proliferação de microrganismos patogênicos, pois a saliva produz proteínas que impedem a replicação viral Carvalho et al. (2021).

Foi relatado também que a cavidade bucal apresenta receptores da $\mathrm{ECA}_{2}$, enzima conversora da angiotensina 2, tornando uma fonte de risco para a infecção por SARS-CoV-2, já que esses receptores da $\mathrm{ECA}_{2}$, possuem grande importância 
na expressão gênica nas células escamosas da língua e glândulas salivares (Villanueva-Sánchez, F. G. et al., 2020). Sabendo que as células epiteliais orais expressam CD147, há uma hipótese em que pode haver infecção por meio da ligação da proteína dos spikes ao cluster de diferenciação 147 (CD147) das membranas celulares. As células do epitélio gengival também expressam CD147, expressão essa aumentada em sítios com periodontite. Por outro lado, (Kara, C. et al., 2020) realizaram uma revisão de estudos e não encontrou resultados mostrando uma relação com patologias orais e COVID 19. Entretanto é possível que doenças bucais possam ter um papel importante em termos de ser um fator de risco para a COVID 19.

\section{Conclusão}

Os estudos demonstraram que há uma relevante associação da COVID-19 com diversas doenças orais. A maioria dos relatos identificaram que pacientes acometidos pelo SARS-CoV-2, e que possuíam doenças subjacentes, tinham mais suscetibilidade para desenvolver infecções orais, que, por meio de diversos mecanismos da mucosa oral, como infiltração de células inflamatórias por meio de liberação de citocinas, causaram danos na saúde dos pacientes, influenciando na gravidade desses casos. Complicações orais não graves também foram relatadas, como ulcerações. Verificou-se que fatores de higiene são primordiais para o desenvolvimento de complicações, pois a desregulação da microbiota oral causa uma disbiose, proporcionando um bom ambiente para proliferação de microrganismos. As doenças periodontais associadas às doenças sistêmicas foram relacionadas à gravidade por COVID-19, embora não se saiba o motivo em casos de fatalidade.

Apesar de alguns autores não terem comprovado uma relação direta das patologias orais e o agravamento da COVID19, devido à poucos estudos de casos, outros, evidenciam que existe sim essa associação, demonstrando os causadores e os mecanismos responsáveis, aqui mencionados. São necessários estudos envolvendo mais casos de periodontite em pacientes com COVID-19, em quadros de diferentes desses pacientes, para que assim, seja comprovado uma melhor associação.

\section{Referências}

Bertolini, M et al. (2020) Periodontal Disease in the COVID-19 Era: Potential Reservoir and Increased Risk for SARS-CoV-2. Pesquisa Brasileira em Odontopediatria e Clínica Integrada, 20.

Bhatia, V et al. (2021). Can Improved Periodontal Health Be A Key Factor In Preventing Severe COVID-19 Complications: An Evidence-Based Review. Advanc Dentistry, 2 (1), 1-4.

Brito, L. F. N. de et al. (2016). Influência do tratamento ortodôntico na reabsorção radicular: uma revisão sistemática. RFO UPF, $21(2), 231-236$.

Cardoso, T. F. et al. (2020). COVID-19 e a Cavidade Bucal: interações, manifestações clínicas e prevenção. Ulakes Journal Of Medicine, 1.

Carvalho, R C L et al. (2021). Atuação do cirurgião-dentista no cuidado de pacientes em unidade de terapia intensiva durante a pandemia da COVID-19. Brazilian Journal of Health Review, 4 (2), 9473-9487.

Dziedzic, A.; \& Wojtyczka, R (2021). O impacto da doença infecciosa por coronavírus 19 (COVID - 19) na saúde bucal. Doenças orais, $27,703-706$.

Falcón-Guerrero, B E.; \& Falcón-Pasapera, G S (2021) Repercusiones en la Cavidad Oral Causadas por la Infección con COVID-19. International journal of odontostomatology, 15 (1), 23-26.

Fiocruz (2021) Impactos sociais, econômicos, culturais e políticos da pandemia. https://portal.fiocruz.br/impactos-sociais-economicos-culturais-epoliticosda-pandemia

Flores, R G.; \& Rodríguez, G Z (2020). Implicaciones bucales por COVID-19. Revisión de tema. Odontol. sanmarquina (Impr.). $2020 ; 23(4)$ : 419-424.

Gatti, M et al. (2020). Radiografia de tórax basal em pacientes com doença coronavírus 19 (COVID-19): associação com dados clínicos e laboratoriais. La $R$ adiologia M edica, 125 (12), 1271-1279.

Harikrishnan, P (2020). Gustatory dysfunction as na early symptom in COVID-19 screening. The Journal of craniofacial surgery. Inferir da literatura até o presente momento? Cenários Odontológicos Em Tempos De Pandemia, p. 238.

Iranmanesh, B et al. (2021). Oral manifestations of COVID-19 disease: A review article. Dermatologic therapy, 34, (1), e14578.

Johnson, I. G. et al. (2021). Dental periodontal procedures: a systematic review of contamination (splatter, droplets and aerosol) in relation to COVID-19. BDJ open, 7 (1), 1-7. 
Research, Society and Development, v. 11, n. 3, e14011326159, 2022

(CC BY 4.0) | ISSN 2525-3409 | DOI: http://dx.doi.org/10.33448/rsd-v11i3.26159

Kara, C., et al. (2020). Is periodontal disease a risk factor for developing severe COVID-19 infection? The potential role of Galectin-3. Experimental Biology and Medicine, 245 (16), 1425-1427.

Kumar, V., et al. (2010). p38 kinase is crucial for osteopontin-induced furin expression that supports cervical cancer progression. Cancer research, 70 (24), $10381-10391$.

Marouf, N., et al. (2021). Association between periodontitis and severity of COVID-19 infection: A case-control study. Journal of clinical periodontology, 48 (4), $483-491$.

Matuck, B. F., et al. (2021). Periodontal tissues are targets for Sars-Cov-2: a post- mortem study. Journal of Oral Microbiology, 13 (1), 1848135.

Mcintosh, K.; Hirsch, M. S.; \& Bloom, A (2020). Coronavirus disease 2019 (COVID-19). UpToDate Hirsch MS Bloom, 5 (1).

Mcintosh, K.; Hirsch, M. S.; \& $\quad$ Bloom, A $\quad$ (2020). Doença $\quad$ de $\quad$ coronavírus $2019 \quad$ (COVID- 19). https://www.cmim.org/PDF_COVID/Coronavirus_disease2019_C OVID-19_UpToDate2.pdf.

Passarelli, P. C., et al. (2020). COVID-19 and oral diseases: How can we manage hospitalized and quarantined patients while reducing risks? Electron J Gen Med. 2020, 17 (6), 238

Pitones-Rubio, V. et al. (2020). A doença periodontal é um fator de risco para doença COVID- 19 grave? Hipóteses médicas, 144, 109969.

Rayet, B.; \& Gelinas, C (1999). Aberrant rel/nfkb genes and activity in human cancer. Oncogene, 18 (49), 6938-6947.

Santos, J. P. A. et al. (2020). Doença periodontal e covid-19: o que podemos inferir da literatura até o presente momento? Cenários Odontológicos Em Tempos De Pandemia, 238.

Sharma, A et al. (2020). How Chronic Periodontitis associated with Systemic Diseases increases the case fatality rate among COVID-19 Patients. Journal of Advanced Medical and Dental Sciences Research, 8 (8), 71-77.

Soares, C. D et al. (2020). Letter to Editor: Oral lesions in a patient with Covid-19. Medicina oral, patologia oral y cirugia bucal, 25 (4), e563.

Sukumar, K.; \& Tadepalli, A (2021). Nexus between COVID-19 and periodontal disease. Journal of International Medical Research, 49 (3), 03000605211002695

Takahashi, Y et al. (2021). Aspiration of periodontopathic bacteria due to poor oral hygiene potentially contributes to the aggravation of COVID-19. Journal of oral science, 63 (1), 1-3.

Villanueva-Sánchez, F. G. et al. (2020). Expressão gênica de receptores ECA2 na cavidade oral e glândulas salivares e seu papel na infecção por SARS CoV2. Revisão da literatura. Odovtos International Journal of Dental Sciences, 22 (3), 87-92.

Yongchaitrakul, T.; Manokawinchoke, J.; \& Pavasant, P (2009). Osteoprotegerin induces osteopontin via syndecan-1 and phosphoinositol 3-kinase/Akt in human periodontal ligament cells. Journal of periodontal research, 44 (6), 776-783.

Zhu, et al. (2020). Um novo coronavírus de pacientes com pneumonia na China, 2019. New England Journal of Medicine. 